\title{
HISTORICAL PHOTOGRAMMETRY AND TERRESTRIAL LASER SCANNING FOR THE 3D VIRTUAL RECONSTRUCTION OF DESTROYED STRUCTURES: A CASE STUDY IN ITALY
}

\author{
G. Bitelli ${ }^{\text {a }}$, M. Dellapasqua ${ }^{a}$, V.A. Girelli ${ }^{a}{ }^{*}$, S. Sbaraglia ${ }^{\text {b }}$, M.A. Tini ${ }^{\mathrm{a}}$ \\ ${ }^{a}$ DICAM, Dept. of Civil, Chemical, Environmental and Materials Engineering, Alma Mater Studiorum University of Bologna, Italy \\ - (gabriele.bitelli, mirko.dellapasqua, valentina.girelli, mariaalessandra.tini)@unibo.it \\ b silvia.sbaraglia@hotmail.it
}

KEY WORDS: Historical images, Close-Range Photogrammetry, 3D modelling, Cultural Heritage, Virtual reconstruction

\begin{abstract}
:
The current dramatic episodes of destruction of archaeological sites have again highlighted the problem of the safeguarding the threatened heritage and, if possible, recovering those damaged by all the armed conflicts of the past.

The historical photogrammetry offers the possibility to recover a posteriori the geometrical and material properties of destroyed structures, reconstructing their 3D model to document, study and maintain their memory, until to support their real anastylosis.

The presented work is about the 3D reconstruction of the civic tower of the little town of Sant'Alberto, near the city of Ravenna, Italy. The tower, as a symbol of resistance and pride of the town's population, was destroyed in December 1944 by German troops in retaliation, when they were forced to leave the area.

A city committee has subsequently collected all the historical evidence concerning the tower, including a series of photographic images that can be used for the photogrammetric reconstruction; the images calibration and orientation have been solved using the geometric information derived by a terrestrial laser scanner survey realized in the area where the tower was originally located.

Despite the scarcity and very poor quality of the available images, the conducted photogrammetric procedure has allowed a complete and qualitatively satisfying object reconstruction, also thanks to the use of geometric constraint tools offered by the chosen software. The integration between the obtained model of the old tower and the 3D TLS survey of the square made it possible to reconstruct the ancient situation of the area.
\end{abstract}

\section{INTRODUCTION}

The need to preserve and document the cultural heritage has become more and more important: the dramatic episodes of destruction of archaeological sites have further highlighted the problem of the safeguarding the threatened heritage and, if possible, recovering those damaged by all the armed conflicts of the past, with the aim of real or virtual anastylosis and conservation of them.

Photogrammetry can play an important role thanks to the large available photographic imagery heritage, historical and current, which offers the advantage of a monitoring over time, both in qualitative and quantitative terms: in fact, the use of images acquired in the past (through the so-called "archival" or "historical" photogrammetry) allows to make comparisons and multi-temporal analysis, supported by metric data. The current technologies make possible also the virtual metric reconstruction of ancient structures; this digital product, referred to details and, sometimes, the entire buildings geometry, can be used to plan interventions, for architectural research, for the historical cataloguing, up to supporting a real anastylosis of the object.

Considering that most of the world significant sites have been photographed under many different viewing conditions, the opportunities offered by photogrammetry are significantly enlarged by using non-metric images, available also on the Internet, especially nowadays thanks to the wide use of social networks that further facilitate sharing of amateur images (Gruen et al., 2004; Ioannides et al., 2013; Maiwald et al., 2017; Snavely, 2007).
In territorial scope, historical photogrammetry (HP) applies especially to the territorial evolution monitoring or to the analysis of natural phenomena, highlighting changes in the morphology of glaciers, volcanoes or landslide soils (Bitelli et al., 2009; Diolaiuti et al., 2009; Gatta et al., 2011; Walstra et al., 2007). In archaeological contexts, also declassified satellite imagery can be used (Bitelli \& Girelli, 2009; Philip et al, 2004), together with historical airborne imagery (Hanson \& Oltean, 2013).

Public administrations can keep organized the local database and often they manage the heritage of photogrammetric imagery, both historical and actual. They can also create tools to allow sharing and web consultation to users, both private citizens and professional operators (Bitelli et al., 2006).

As for Cultural Heritage, a good part of the historical documents is accessible in the published literature or in public archives and libraries (Wiedemann et al., 2000). Images acquired usually by individuals, if related to historical epochs, may not be easy to find. However, this rich heritage of images is particularly valuable because it is often the only way to study and reconstruct the geometry of destroyed, altered or counterfeit objects (Bitelli et al., 2007).

A HP survey presents many more difficulties compared to a traditional one: firstly, the research of archival photographs can take considerably longer time than the common procedures of collecting and processing photos of an existing object. In addition, imagery is usually not in a form that is suitable to processing at least by traditional photogrammetric methods: the images are uncalibrated and the total or partial lack of information regarding the camera models impedes an 
approximate knowledge of the interior orientation parameters. Illumination, resolution, and image quality are widely variable and uncontrolled; especially, the old photos are commonly in grey scale, they are small and with low photographic quality. Their quality degrades further when images are obtained from digitization of historical books, in which the figures in some cases are even clippings of the original photographs. Also, since the set of photos was not captured for metric purposes, it usually has a geometric distribution very far from that suitable for photogrammetric applications and the number of available images is often not sufficient to approach the weakness of the geometric model. It must also be considered that for a complete description of the object, depending on the purpose of the process, may be necessary to reconstruct not only its shape and geometry, but also its original location relative to the surrounding context.

The photogrammetric processing of such sets of images must therefore take advantage of special processing tools, such as calibration procedures for the images internal parameters estimation or the imposition of geometric constraints based, for example, on the object shape. Then, if the surrounding environment remained largely unchanged compared to that shown in the pictures, the HP data can be integrated with rigorous metrics information, acquired from the current reality.

The presented case study is an example of application of HP for the virtual reconstruction of a destroyed structure, the civic tower of Sant'Alberto, (Ravenna, Italy), ruined during World War II, because of a German reprisal. Since the urban context in which the tower was inserted consists of historic buildings that today maintain the same architectural characteristics of the time, a terrestrial laser scanner (TLS) survey was performed to provide a large number of control points to support the photogrammetric process.

After a brief historical background of the monument, the methods used to obtain the three-dimensional model of the tower and its position and orientation related to the neighboring buildings will be described.

\section{THE CIVIC TOWER OF SANT'ALBERTO (ITALY)}

Sant'Alberto is a small village located north of the Province of Ravenna, on the borders of the river Po Delta Park and the valleys of Comacchio, recognized as a "UNESCO World Biosphere Reserve".

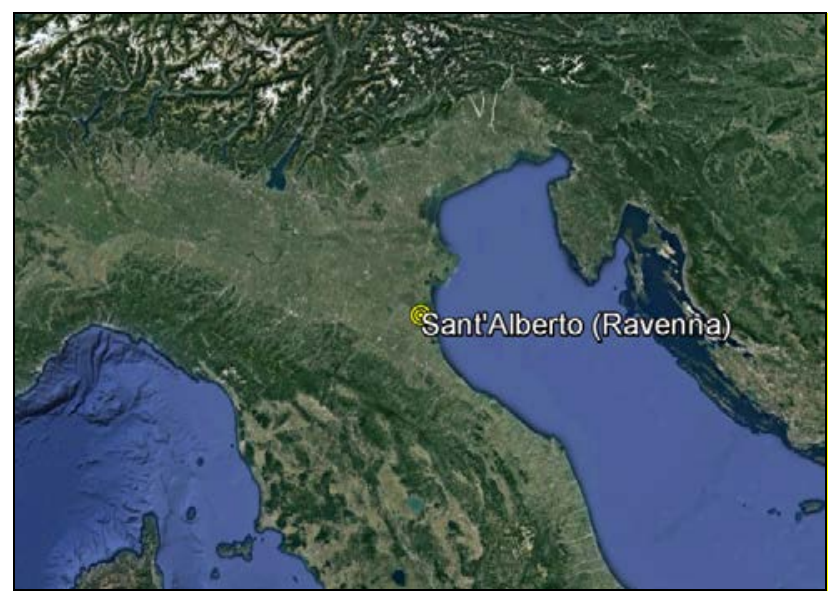

Figure 1. Location of Sant'Alberto town in Italy.
The civic tower of Sant'Alberto was erected in 1854 in the main square of the village; built in facing brick with a scarp wall as basement, it was about 24 meters high, with a square base with a side of about 4 meters. The four-sided roof was made of bent tiles: inside there was a spiral staircase to reach the clock and the bell at the top.

By the end of the 1920s, the tower was raised by about 2 meters, creating at the top a terrace, with three merlons at the four corners.

During the World War II a partisan command had hoisted the Italian flag on its top, but when Sant'Alberto was occupied by the Germans on September 8, 1943, the troops removed the flag and began using the tower for sighting, to follow the movements of allied forces, slowly advancing to free the Italian territory. World War II was coming to a standstill, when the Germans realized that they were no longer able to resist the offensive, and before leaving the country, they decided to destroy the tower, reducing it to a pile of rubble on December 13, 1944.

In the early 50s, the City of Ravenna obtained compensation by the Civil Engineering Department for war damages, but the amount expected for the tower reconstruction was used for other most urgent interventions.

Since the '90s, thanks to the strong will of citizenship a "Promotion Committee for the reconstruction of civic tower of Sant'Alberto" was founded, with the aim of collecting, cataloguing and preserving the rich historical documentation relative to the tower, even in support of a possible project of the monument anastylosis.

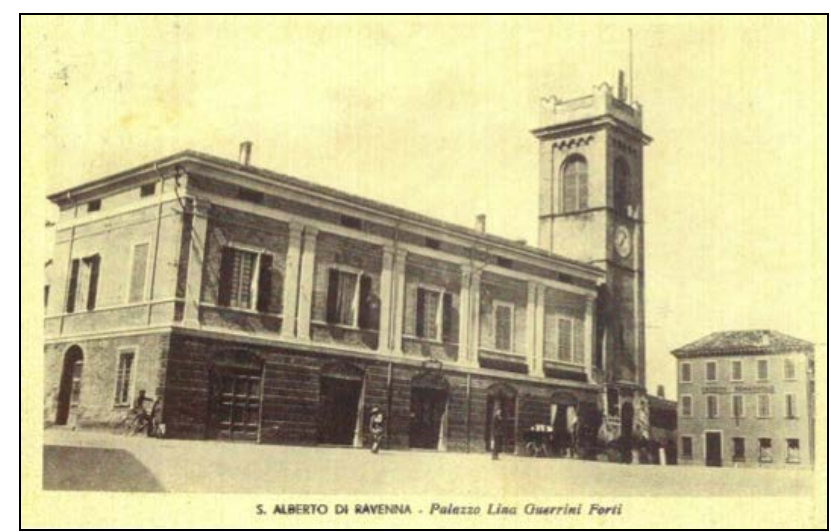

Figure 2. The civic tower in its original position in Garibaldi square (postcard from private collection).

\section{3D VIRTUAL RECONSTRUCTION PROCESS}

The 3D model of the tower was rebuilt by photogrammetry using only historical images. A terrestrial laser scanner survey of the neighbouring area was performed for the identification of control points to be used to support the processing.

The performed phases are schematised in Figure 3 flowchart.

The search for the photographic documentation was the most expensive phase of the entire process in terms of time, due to the difficulty of finding sources: historic images have been recovered in the library archives, documentary collections of cooperatives and private citizens.

The recovered images are in black and white and, in most cases, have poor photo quality, going back to the early ' 900 . 
The resolution is lower than that of the images commonly used for metric purposes, and it is variable depending on the media on which the images have been printed and on the subsequent scanning operation.

Some images also present a degradation of the print support, others are postcards retouched in the main lines to create a sense of represented reality.

Obviously, any information about the cameras used for the acquisition is unknown.

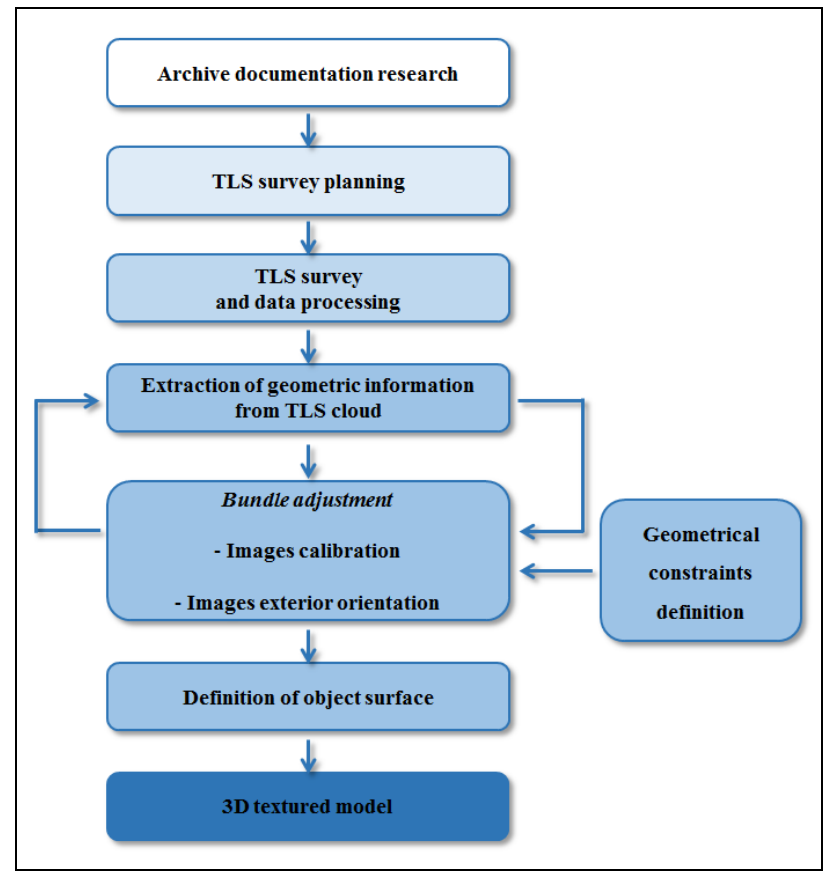

Figure 3. Workflow of the 3D virtual reconstruction.

Based on quality and resolution, a set of images were selected, that allowed the photogrammetric reconstruction of all four sides of the tower.

In Figure 4, which represents the main survey elements, the viewpoints of the images used for the tower model reconstruction are shown.

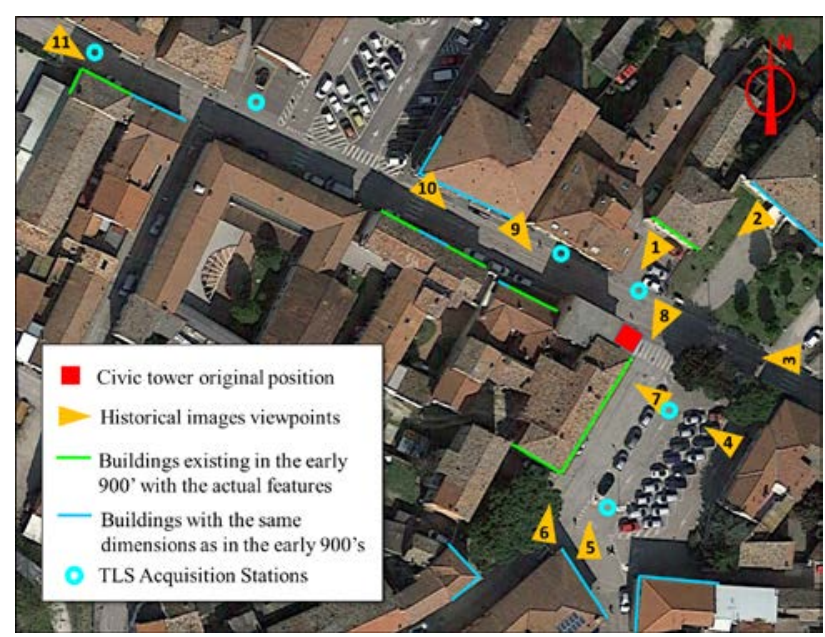

Figure 4. The main survey elements and the tower original position.
It is clear that the historical images acquisition geometry is quite disorganized and irregular; in particular, the most critical side is the North-West direction, in which the images 9, 10 and 11 have a few elements visible in common to the other images in the set.

The historical images viewpoints are predominantly from the bottom to the up, because acquired approximately at ground level: this fact does not allow viewing the roof of the tower, where information is not available.

The base of the tower is not visible in many pictures, because it is covered by numerous people in the square, the area where the main events and markets in the town took place.

Finally, since the tower was built immediately behind the neighbouring buildings, it was only possible to reconstruct the top parts of the Southwest and Northwest sides, because the remaining portions are not visible in the images.

The planning of the topographic survey has been realized after an accurate inspection, necessary to identify which buildings, among those still present in the area, have retained the characteristics coincident with those represented in the historical images, and so useful to identify photogrammetric control points.

In Figure 4, the buildings present at the time of the images but which have retained only external dimensions are highlighted with blue coloured segments; instead the facades that have maintained the same architectural characteristics of the early '900 are highlighted in green.

For the survey used as support for the photogrammetric process, given the extent of the area, the TLS technique has been chosen, to be able to measure in the shortest time the most elements potentially useful in the images external orientation.

The TLS survey was executed by 6 scanning positions, distributed as shown in Figure 4.

The true colour point clouds were acquired with the RIEGL VZ400 system, characterized by a precision of $3 \mathrm{~mm}$, up to distances of 400 meters.

On the walls of potentially useful buildings (highlighted by blue and green lines in Figure 4) points spacing $3 \mathrm{~mm}$ were acquired. The scans were then aligned on the basis of tie points manually collimated and with the application of ICP algorithms; the clouds have been referred to a local reference system, made vertical in one of the stations.

The photogrammetric process was performed by the monoscopic photogrammetric software PhotoModeler Scanner (Eos Systems Inc.)

This software was chosen because it is particularly suited to the development of so unconventional photogrammetric data, allowing to work with a few convergent images.

The images orientation was performed manually collimating tie and control points, conveniently selected by the operator in number and distribution on the images.

Because the software uses the analytical model of the bundle adjustment, it is possible to use images acquired from different cameras and with interior orientation parameters unknown. For each image were estimated the focal length and the principal point position.

In addition, by importing laser data, the system allows the control points extraction directly from the TLS pointclouds.

Finally, this software allows the introduction of geometric constraints, for example parallelism, squareness, verticality of segments, etc., between the vector elements that describe the object model. In particular, this possibility has been extremely helpful in this case, to compensate for the weakness of the 
available images geometry, allowing to take advantage from the simple and regular geometric tower characteristics.

In figure 5 are shown the phases of the photogrammetric process:

- a) the generated 3D vector model with some tie and control points (in red) and the representation of the position of 3 of the historical images; in red is also highlighted one of the quadrilaterals with which the tower side surface have been reconstructed in a geometrically simplified form;

- b) collimation of a control point in the TLS cloud (coloured with an artificial shaded grayscale) and in the images;

- c) the phase of the insertion of the geometric constraints; some segments linked by a mutual parallelism constraint are highlighted in green.
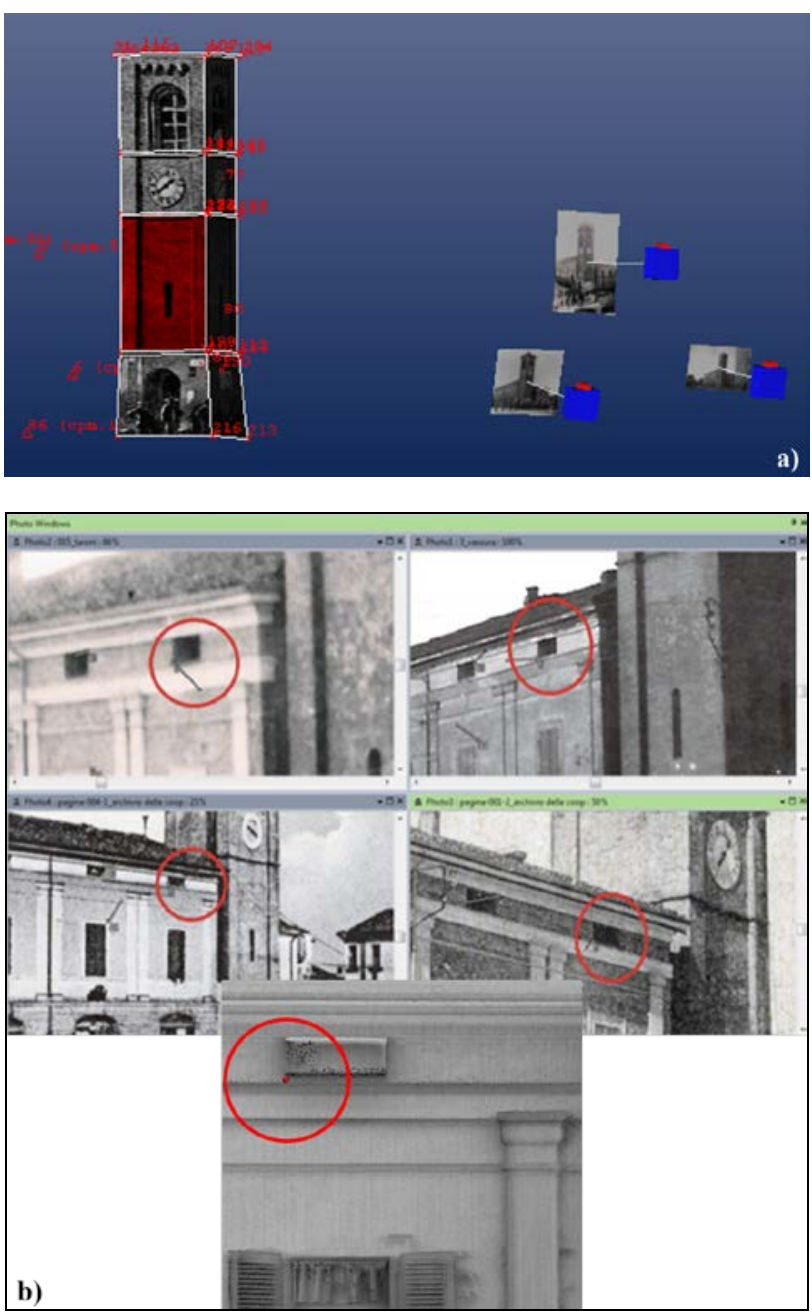

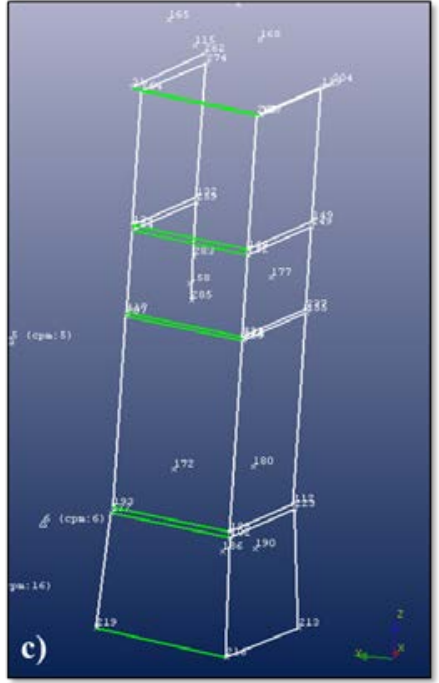

Figure 5. Phases of the 3D model photogrammetric restitution.

For the images exterior orientation and the reconstruction of the tower, about 70 three-dimensional points were collimated; 20 of these have coordinates extracted from the laser clouds. The points were carefully chosen and collimated, to obtain the best possible geometric distribution. The collimation on the images has been performed only when the homologous points were clearly visible, so as to avoid the superimposition of additional noise to an already weak analytical model because of the acquisition geometry. In addition, about 30 geometric constraints have been imposed, mainly regarding parallelism and orthogonality between segments.

The tower has been reconstructed starting from the edegs of the architectural elements and the lines that describe the main geometric components. The side surfaces have been simplified with quadrangles, textured by the most nadiral images.

As expected, because of the images distribution shown in Figure 4, it was not possible to orient the images of the NorthWest side with the other acquired in the square, because the few reliable common elements have proved inadequate.

The remaining images, also thanks to the used geometric constraints, have however allowed to reconstruct the geometric elements of the visible upper part of this side.

The surface texturing has been later performed in a software specific for the laser data processing, considering the vector model of the side as a simple mesh consisting of macrotriangles (Figure 6).

The mesh has been manually coloured, identifying homologous points between the 3D model and a portion of the image 11, shown in Figure 7, which offers a good photographic quality and a perfectly nadir view of the tower side, even if the tower is very far (see Figure 4 for the position and orientation of the historical image). 

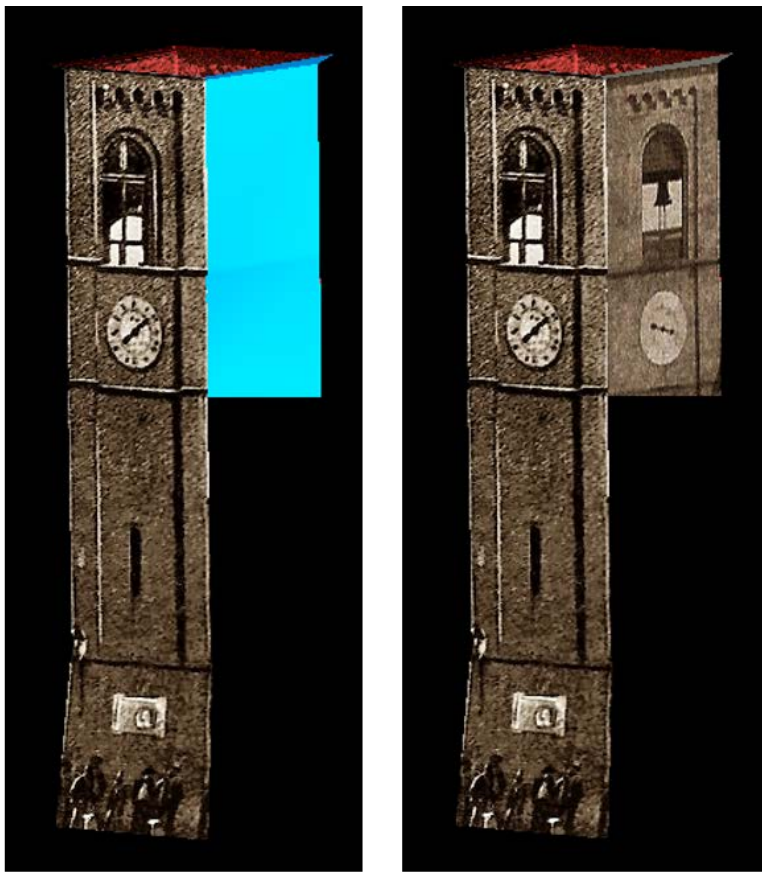

Figure 6. Identification and texturing of the 3D model surfaces.

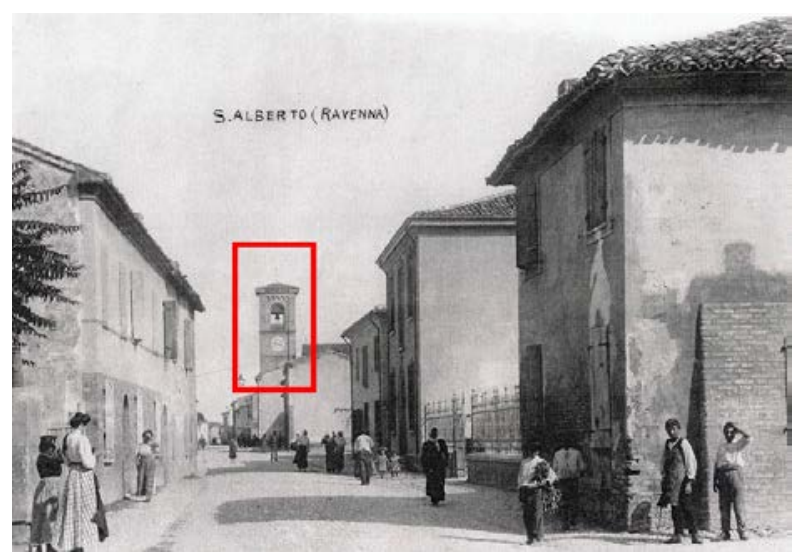

Figure 7. The historical image used to texture the North-West side of the tower (picture from private collection).

\section{RESULTS}

The complete photogrammetric 3D model and the true color cloud obtained from the TLS survey of the area surrounding the tower have been used to virtually replace, but in a rigorous metric way, the civic tower in the current context of the square, inserted in the position where once was placed (Figure 8).
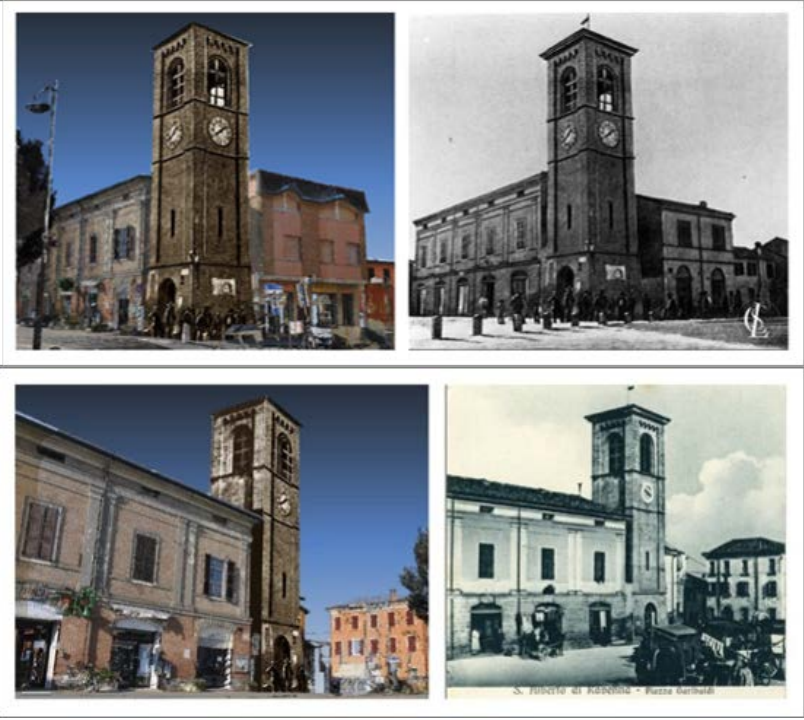

Figure 8. The 3D model of the tower inserted in the TLS cloud of the current context (on the left), from the same viewpoints and in comparison with some historical images (on the right).

Upper images: Eastern view; lower images: Southern view.

The evaluation of the metric quality of the resulting model, useful to also establish its potential use in support of the project of a possible concrete reconstruction of the tower, was performed comparing the photogrammetric model and that obtained by TLS.

In particular, the differences between the $3 \mathrm{D}$ coordinates of some points and the lengths of some distances have been calculated. These items were chosen on the prospect of Guerrini-Forti palace, overlooking the square to the left of the original position of the tower (Figure 2).

This building, having preserved intact the architectural characteristics of the early ' 900 , has been a fundamental base of metric information for the realization of the entire project.

In Figure 8 are shown the elements measured on photogrammetry and laser cloud, artificially coloured with a grayscale shading algorithm to emphasize the architectural discontinuity; the points are in red, in green the horizontal distances, in light blue the vertical ones.

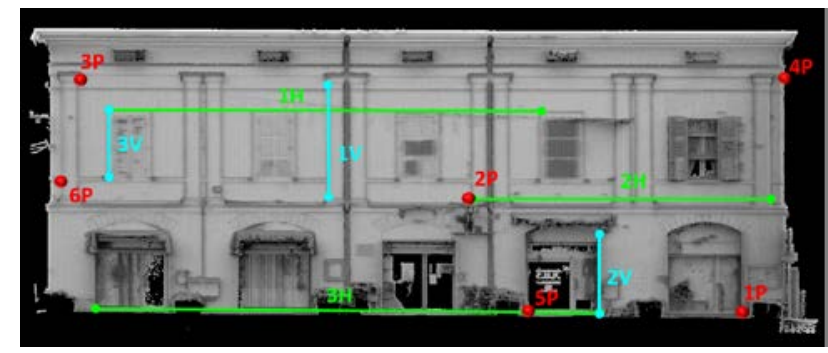

Figure 9. Elements chosen on the Guerrini-Forti palace façade, used for the comparison between the photogrammetric and the TLS model. 


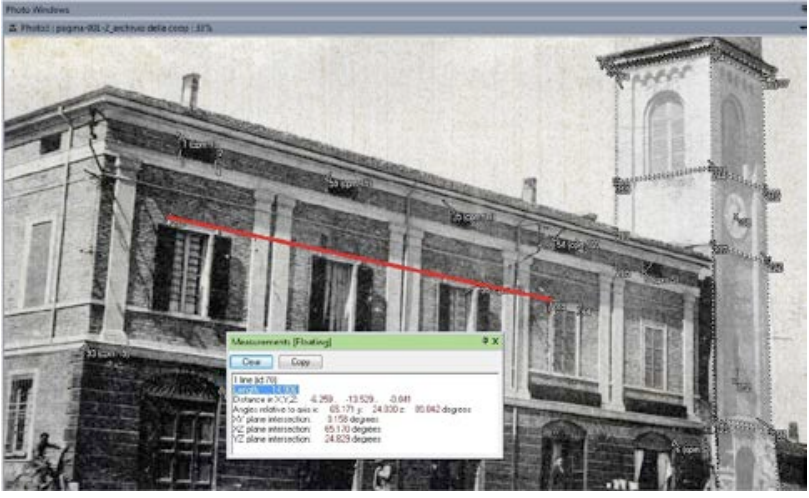

Figure 10. Extraction of one horizontal distance from the photogrammetric model.

As shown in Table 1 and 2 the differences are in the order of some centimetres, largely satisfactory, considering the images characteristics and the work purposes.

\begin{tabular}{|l|c|}
\hline Distance & $\begin{array}{c}\text { Difference between } \\
\text { TLS and photogrammetry }\end{array}$ \\
\hline $1 \mathrm{H}$ & 0.097 \\
$2 \mathrm{H}$ & 0.009 \\
$3 \mathrm{H}$ & 0.034 \\
$1 \mathrm{~V}$ & 0.067 \\
$2 \mathrm{~V}$ & 0.061 \\
$3 \mathrm{~V}$ & 0.022 \\
\hline Average & $\mathbf{0 . 0 4 8}$ \\
\hline
\end{tabular}

Table 1. Distance difference (absolute values) between TLS and photogrammetric models, in meters.

\begin{tabular}{|l|c|c|c|}
\hline \multirow{2}{*}{ Point } & \multicolumn{3}{|c|}{$\begin{array}{c}\text { Difference between } \\
\text { TLS and photogrammetry }\end{array}$} \\
\cline { 2 - 4 } & $\Delta \mathrm{x}$ & $\Delta \mathrm{y}$ & $\Delta \mathrm{z}$ \\
\hline P1 & 0.036 & 0.135 & 0.042 \\
P2 & 0.050 & 0.018 & 0.007 \\
P3 & 0.086 & 0.007 & 0.063 \\
P4 & 0.000 & 0.001 & 0.000 \\
P5 & 0.006 & 0.057 & 0.046 \\
P6 & 0.022 & 0.047 & 0.029 \\
\hline Average & $\mathbf{0 . 0 3 3}$ & $\mathbf{0 . 0 4 4}$ & $\mathbf{0 . 0 3 1}$ \\
\hline
\end{tabular}

Table 2. 3D coordinates difference (absolute values) between

TLS and Photogrammetric models, expressed in meters.

\section{CONCLUSIONS}

In the present study, the technique of "historical photogrammetry" was applied, with the aim of creating a 3D model of a no longer existing object of historical and architectural interest, the civic tower of Sant'Alberto town. Some aspects and problems related to the whole process (in particular, the poor quality of the available historical photographic material, which has made however possible the orientation and restitution process, even if any data of the cameras was available) have been dealt with.

A laser scanning survey was conducted in the area with the aim of constitute the reference database for the subsequent photogrammetric operations carried out in the laboratory.

As regards the part of data processing, it should be noted that the correct model restitution is due in particular to the success of bundle adjustment with images calibration procedure.

Images with a convergence angle as wide as possible have been used and characterized by different acquisition distances: the selection of the historical images was a compromise between the geometric configuration and the availability.

In addition, the orientation and restitution operations have been executed in a semi-automatic approach, in some case assisted by the automatic tools offered by the software; it is underlined that the 3D model restitution has been successfully processed by means of a specific software functionality that allowed to insert some geometric constraints.

Taking as reference an ancient building adjacent to the tower, the Guerrini-Forti Palace, the accuracy in the photogrammetric model could be evaluated through some sample measures. It has proven to be metrically reliable and, despite the enormous lacks in the quality and in the number of the used images, the object has been reconstructed in its $3 \mathrm{D}$ form with a satisfying metric accuracy.

The representations obtained by the insertion of the photogrammetric 3D model in the TLS cloud obtained for the current surrounding area are characterized by a good visual impact.

The importance of historical images is confirmed, not only as information heritage that faithfully reproduce the photographed object, but sometimes as unique tools to rebuild a lost reality, both in qualitative and quantitative terms.

In particular, this case highlights the extreme versatility and flexibility of photogrammetry, in relation to the survey and the data processing. If a large amount of historical images is available, different approaches, like Structure from Motion, can offer nowadays the possibility of an automatic processing.

The work was inspired by the analysis of the methods applied in other cases of virtual reconstruction, concerning lost objects of architectural and cultural heritage. With the constant evolution of information technologies associated with the dissemination and sharing of data by the web and the social networks, it is always more and more easier to find historical and amateur images, that can provide the base from which 3D models of destroyed or not more existing objects can be derived, also where every trace material is gone lost.

\section{ACKNOWLEDGEMENTS}

The authors would like to thank the members of the "Promotion Committee for the reconstruction of civic tower of Sant'Alberto" for the support offered to collect historical imagery.

\section{REFERENCES}

Bitelli G., Gatta G., Giorgini G., Minghetti A., Mognol A., Paselli E., 2006: "Recupero a fini metrici di fotogrammi aerei storici per lo studio delle dinamiche territoriali in ambito urbano: un caso di studio", Atti 10a Conferenza Nazionale ASITA, Bolzano, pp. 355-360. 
Bitelli G., Gatta G., Landuzzi A., Vittuari L., Zanutta A., 2009: "La fotogrammetria digitale di archivio per lo studio multitemporale di un'area di frana nelle Prealpi vicentine”, Atti 13a Conferenza Nazionale ASITA, Bari, 1-4 December 2009.

Bitelli G., Girelli V.A., Marziali M., Zanutta A., 2007: “Use of historical images for the documentation and the metrical study of Cultural Heritage by means of digital photogrammetric techniques”, International Archives of Photogrammetry and Remote Sensing, Vol. XXXVI-5/C53, pp. 141-146.

Bitelli G., Girelli V.A., 2009: "Metrical use of declassified satellite imagery for an area of archaeological interest in Turkey”. Journal of Cultural Heritage, vol. 10S, 35-40.

Diolaiuti G., D’Agata C., Meazza A., Zanutta A., Smiraglia C., 2009: "Recent (1975-2003) changes in the Miage debriscovered glacier tongue (Mont Blanc, Italy) from analysis of aerial photos and maps", Geografia Fisica e Dinamica Quaternaria, 32, pp. 117 - 127.

Gatta G., Landuzzi A., Zanutta A., 2011: "La fotogrammetria d'archivio per lo studio della frana di Scascoli (Bologna)”, Atti 15a Conferenza Nazionale ASITA, Reggia di Colorno, Parma, 15-18 November 2011.

Gruen A., Remondino F., Zhang L., 2004: "Photogrammetric Reconstruction of the Great Buddha of Bamiyan, Afghanistan”, The Photogrammetric Record, 19, pp. 177-199.

Hanson W.S., Oltean I.A., 2013: “Archaeology from Historical Aerial and Satellite Archives”, Springer-Verlag, New York.

Ioannides M., Hadjiprocop A., Doulamis N., Doulamis A., Protopapadakis E., Makantasi K., Santos P., Fellner D., Stork A., Balet O., Julien M., Weinlinger G., Johnson P.S., Klein M., Fritsch D., 2013: “Online 4D Reconstruction Using Images Available Under Open Access”, ISPRS Ann. Photogramm. Remote Sens. Spatial Inf. Sci., II-5/W1, pp. 169-174.

Maiwald F.,Vietze T., Schneider D., Henze F., Münster S., Niebling F., 2017: "Photogrammetric Analysis of Historical Image Repositories for Virtual Reconstruction in the Field of Digital Humanities", International Archives of the Photogrammetry, Remote Sensing and Spatial Information Sciences, XLII-2/W3, pp. 447-452.

Philip G., Donoghue D. N. M., Beck A. R., Galiatsatos N., 2002: "CORONA satellite photography: an archaeological application from the Middle East.”, Antiquity, 76 (291), pp. 109-118.

Snavely N., Seitz S.M., Szelisk R., 2007: "Modeling the World from Internet Photo Collections", International Journal of Computer Vision, 80 (2), pp. 189-210.

Walstra J., Dixon N., Chandler J. H., 2007: "Historical aerial photographs for landslide assessment: two case histories", Quarterly Journal of Engineering Geology and Hydrogeology, 40(4), pp. 315-332.

Wiedemann A., Hemmleb M., Albertz J., 2000: "Reconstruction of historical buildings based on images from the Meydenbauer archives", International Archives of Photogrammetry and Remote Sensing, 35(B5), pp. 350-353. 